\title{
The Emergency Position Reporting System and a Sample Application
}

\author{
Emin Borandag \\ Department of Software \\ Engineering \\ Celal Bayar University \\ Manisa, Turkey
}

\author{
Fatih Yucalar \\ Department of Software \\ Engineering \\ Celal Bayar University \\ Manisa, Turkey \\ Deniz Kilinc \\ Department of Software \\ Engineering \\ Celal Bayar University \\ Manisa, Turkey
}

\author{
Akin Ozcift \\ Department of Software \\ Engineering \\ Celal Bayar University \\ Manisa, Turkey
}

\begin{abstract}
Global Positioning System (GPS) is a space-based navigation system that provides location and time information globally on an unobstructed line of sight on Earth under all weather conditions with four or more satellites. It is a satellite network that sends information which is encoded regularly. The location of the person using GPS system can be found precisely by measuring the distance between the person and satellites. The Emergency Position Reporting System (EPRS) was developed is aiming to reduce the problems people experience when they call the emergency numbers by using GPS technology in mobile phones. Today, tens of thousands of unsubstantiated or false calls are received by existing emergency call systems. These unsubstantiated or false calls result in busy phone lines and lead to long waiting times to reach the emergency phone numbers. In these systems, there are also major problems such as occurrence of death due to the failure to describe the address correctly and losing time while describing the address. EPRS will be used in order to eliminate these major problems and overcome the problems such as having difficulties to locate the address of the incident.
\end{abstract}

\section{Keywords}

GPS, Emergency Location Reporting System, Location, The Route Calculated

\section{INTRODUCTION}

Today, tens of thousands of unsubstantiated or false calls are received by existing emergency call systems. These unsubstantiated or false calls result in busy phone lines and lead to long waiting times to reach the emergency phone numbers. In these systems, there are also major problems such as occurrence of death due to the failure to describe the address correctly and losing time while describing the address. The Emergency Position Reporting System (EPRS) is developed in order to eliminate such problems and overcome the problems such as having difficulties to locate the address of the incident. The system developed uses Global Positioning System (GPS) technology.

The Emergency Position Reporting System (EPRS) to be developed is aiming to reduce the problems people experience when they call the emergency numbers by using GPS technology in mobile phones. EPRS will consist of 3 different platforms including mobile application, web-based application and tablet application. The location of the person using the mobile platform application of EPRS for emergency notification will be detected. In addition, the person using mobile platform application of EPRS will be able to send the photo of the emergency scene to the operator.

The warnings will be assessed by the operator using webbased platform of EPRS and the information about the incident reported will be sent to the nearest vehicle instantly. After the warning information is confirmed by an authorized person in the vehicle, the shortest route will be calculated by the tablet application of EPRS.

In the second section of the article, related studies in the literature are reviewed. In the third section, navigation technologies are discussed. In the fourth section, the study performed is presented. In the last section, information obtained as a result of the study are presented.

\section{LITERATURE}

"PublicFeed", is a location-based news app that completely eliminates the boundary between publisher and audience. Although it is not an emergency location system, it is an application that allows users to transmit information to each other. In this application, news can be shared and texts not exceeding 300 characters, photographs and/or audio recordings can be exchanged. PublicFeed has both IOS and Android Applications [1].

"Emergency Call Location Determination System" is an application established by General Commandership of Gendarmerie in order to follow notifications made by citizens to notice-emergency line 156 . One of the most important features of this system is determining location data of the GSM phone of the victims in the emergency and showing location data of the victims on the map $[2,3]$.

"Lifeguard Mobile Health Project" is a mobile application that directs the nearest volunteer lifeguard to the incident by using the location information in order to provide the first aid 
support which may be vital for patient until the ambulance reaches the location [4].

\subsection{GPS and Navigation Technology}

GPS (Global Positioning System) is a regularly encoded satellite network that sends information and it is a system that allows us to identify the exact place on earth by measuring the distance between the satellites on a global scale. This system consists of constantly advancing satellites of the US Department of Defense in their orbits. The system supported by the Department of Defense is accessible by anyone with a GPS receiver [5, 6, 7]. The satellites emit radio signals and GPS receivers on Earth determine location by interpreting these signals. GPS project was developed in 1973 by with the integration of some opinions emerged in the first few attempts including series of hidden engineering studies from the 1960s in order to overcome the limited functionality of previous navigation systems. GPS was designed and operated with 24 satellites by US Department of Defense (DoD). It has become fully operational in 1994. The system was strengthened with the inventions of Bradford Parkinson, Roger L. Easton and Ivan A. Getting [8]. In Figure 1, location detection by GPS is illustrated.

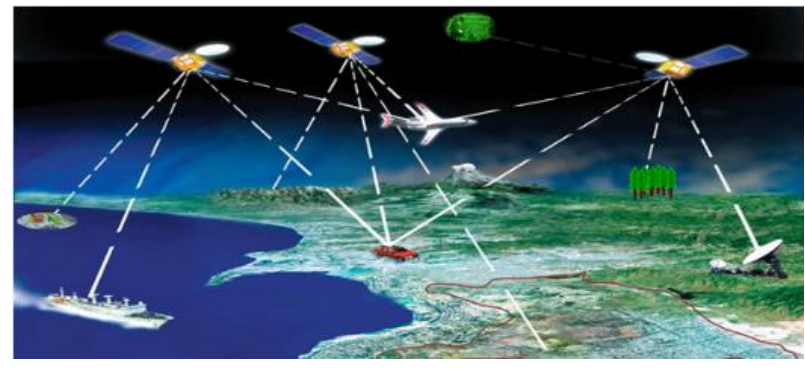

Figure 1. Location detection by GPS

Navigation system enables us to achieve the shortest and fastest way to the destination address by using GPS technology. In this way, we can easily reach a new address without asking to anyone. Figure 2 shows navigation layers.

The navigation system is comprised of three layers laid over one another. These;

$\begin{array}{ll}\text { - } & \text { Hardware } \\ \text { - } & \text { Engine } \\ \text { Map }\end{array}$

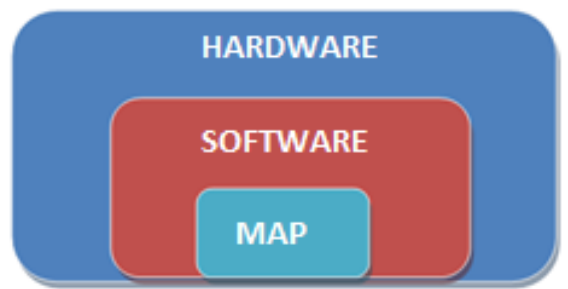

Figure 2. Navigation Layers

The person using the navigation system is informed about the location to be arrived by voice and video. The navigation system re-calculates the new route and determines the most appropriate route if the person goes to a wrong direction [9, 10]. A navigation device is provided as an example in Figure 3.

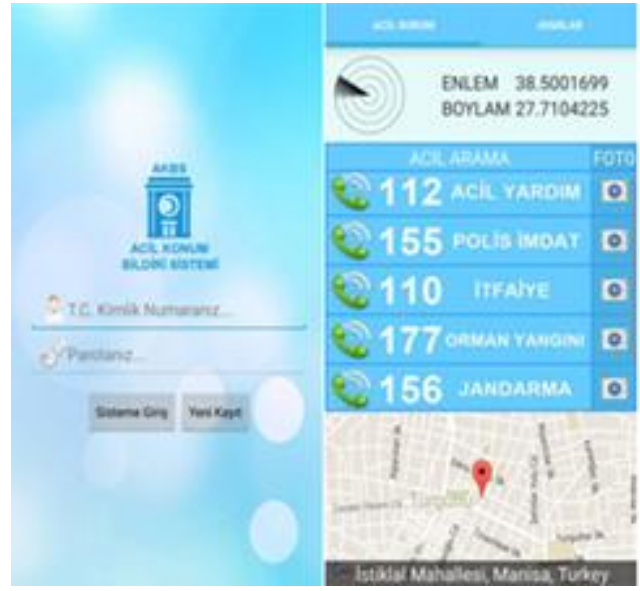

Figure 3. Personal Navigation Device (PND)

\subsection{The System Developed}

Speed and the location of the place to be arrived is very important for transportation. These factors become more important in case of an emergency. For this purpose, the Emergency Position Reporting System (EPRS) is developed. The purpose of the system is reducing the time spent to arrive the emergency site. Another purpose of the system is reducing the time spent for making emergency calls to zero. The person making an emergency call will not be required to tell the location of the incident. In this way, the emergency vehicle will instantly be directed to the site instead of explaining the address. The closest vehicles will be listed. Then, the nearest vehicle will arrive the emergency site in a shortest time possible.

In this context, an Android-based application is developed to make emergency notifications. In addition, a web-based platform is developed in order to locate the emergency site and location of vehicles that will reach the site. GPS signals are used to determine the location of the emergency notification and location of vehicles that will reach the site correctly. Furthermore, a mobile-based application is developed for vehicles that will reach the emergency site. In this way, the fastest route will be calculated by using the location of emergency and vehicle locations and emergency vehicles will arrive the site quickly. Responsive algorithms and Google APIs are used to select the closest emergency vehicle and determine the route between the vehicle and emergency site.

Mobile Application receives the location information of the person by using the GPS system case of emergency. The screenshot of mobile application is shown in Figure 4.

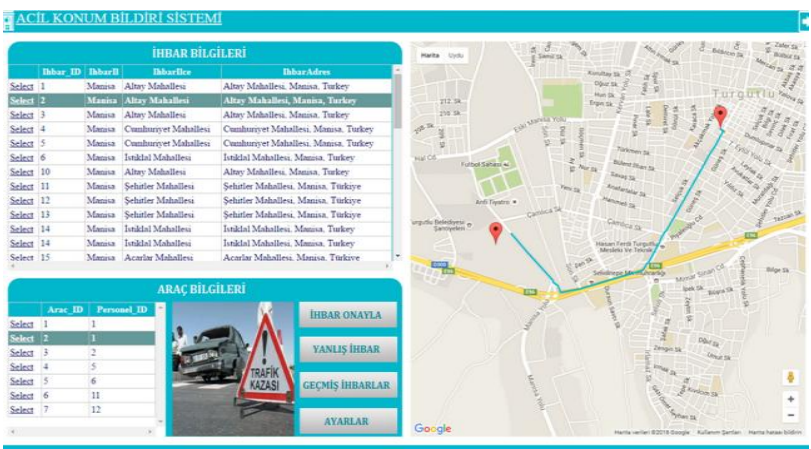

Figure 4. Homepage of the Mobile Application 
The system that will be used by the operator transmits the emergency calls listed and locations of the incidents to the relevant emergency vehicles. The emergency incidents will be listed on a screen in front of the operator. In addition, the emergency vehicles will be monitored. In Figure 5, the screenshot of the system that will be used by the operator is shown.

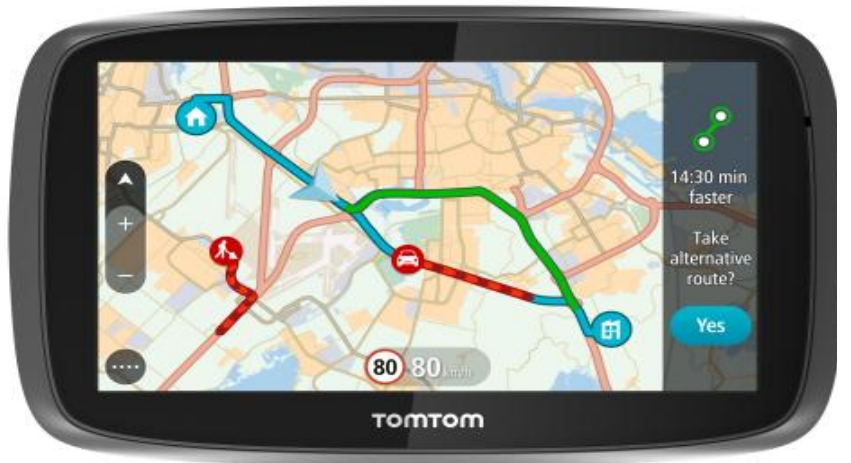

Figure 5. The System That Will be used by the Operator

The system that will be used in the emergency vehicle will display the emergency notification on a screen and inform the authorized person in the vehicle. Then, the shortest route will be calculated between the vehicle and emergency site. The system will assist the vehicle to arrive the emergency site in the shortest time possible.

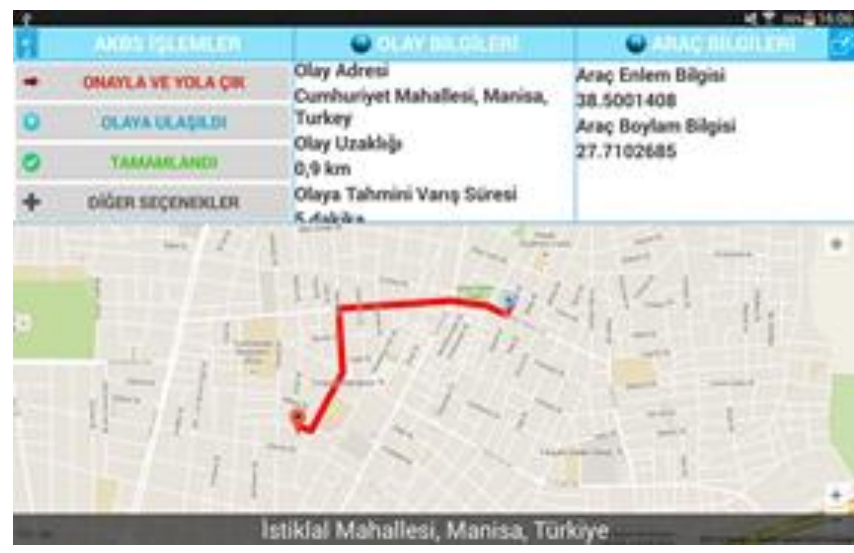

Figure 6. The application screen of the emergency vehicle system is shown in Figure 6.

This system will enable emergency vehicles to reach the emergency site in the shortest time possible. In addition, receiving the location information by using the GPS will shorten the duration of emergency call and reduce the workload in the call center. The authorized person confirms the location of incident determined by using the GPS and then emergency personnel intervene the site more cautiously and quickly with assistance of the system that is strengthened with location information, traffic control, finding the shortest route, photo of the emergency site.

\section{CONCLUSION}

Detecting the location of emergency will allow emergency staff to reach the site in the shortest time and prevent loss of life caused by any delay. For this purpose, the GPS has been examined carefully. People have difficulties to give the directions and tell wrong addresses in case of an emergency. As a result of these studies, the location of person will be determined by GPS and such problems will be eliminated. Photos of the scene will be received along with the location. This feature will provide information to the people in the emergency vehicle about the emergency scene. It will be easier for people in the emergency vehicle after receiving the location information of the emergency scene. The system that will be used in the emergency vehicle will display the emergency notification on a screen and inform the authorized person in the vehicle. Then, the shortest route will be calculated between the vehicle and emergency site. In this way, the emergency vehicles will reach the emergency site in the shortest time possible.

\section{REFERENCES}

[1] Türkiye'de geliştirilen PublicFeed, konum tabanlı bir "ayakl1 gazete" uygulaması http://webrazzi.com/2015/06/18/turkiyede-gelistirilenpublicfeed-ayakli-gazete/, Online (March 2016).

[2] ÂCİL ÇAĞRI KONUM BELİRLEME SİSTEMİ, (81) İL J.KOMUTANLIĞINCA KULLANILMAYA BAŞLANMIŞTIR

http://www.jandarma.tsk.tr/basin/guncel/2011/GH2011M ayis02.doc, Online (March 2016).

[3] Jandarma, İhbarlar İçin 'Acil Çağrı Konum Belirleme Sistemi' Kurdu http://www.haberler.com/jandarmaihbarlar-icin-acil-cagri-konum-belirleme-3463852haberi/, Online (March 2016).

[4] Online: http://www.ayaklicankurtaran.com/ (April, 2016).

[5] GPS Public Information System. "What's GPS?". Web Address: http://www.gps.gov/applications, (March, 2016).

[6] The Library of Congress. "What is a GPS? How does it work?".

(2011) http://www.loc.gov/rr/scitech/mysteries/global.html

[7] R. Maddison and C. Ni Mhurchu, "Global positioning system: a new opportunity in physical activity measurement", International Journal of Behavioral Nutrition and Physical Activity, 6(73), 2009, doi: 10.1186/1479-5868-6-73.

[8] B. L. O'Leary, A. Darrin, (2009), "Handbook of Space Engineering, Archaeology, and Heritage". Hoboken: CRC Press. pp. 239-240. ISBN 9781420084320.

[9] Başarsoft Bilgi Teknolojileri A.Ş. "Navigasyon Nedir?", (2012). Web Address: http://www.basarsoft.com.tr/Navigasyon, (March, 2016).

[10] Navturk Navigasyon Ltd.Şti. Navigasyon yazılım ekranlar1. (2005-2011). 